ID_INVESTIGACIONES

\title{
DE RÍO Y PRADERA, MONTE Y CHACRA, PUERTO Y FÁBRICA. Paisaje y patrimonio en el litoral del río Uruguay
}

\author{
Walter Daniel Castelli
}

Arquitecto Sede Salto, Profesor en la Cátedra de Historia de la Arquitectura Nacional

Facultad de Arquitectura - Universidad de la República.

\section{RESUMEN}

Lectura de la historia del territorio a través de sus formas y comprensión del concepto de patrimonio a escala del territorio, desde las identidades territoriales de la región litoral del Río Uruguay.

Observación de variados modos de interrelación del agua y la tierra, elementos fundantes de este territorio, y la multiplicidad de formas construidas como lugar de vida y trabajo, por las comunidades humanas residentes.

Dos casos, ilustrativos de la Historia de la ganadería, el cuero y la carne, que desde raíz común han desarrollado procesos diferentes, construyendo la diversidad de este perfil de paisaje cultural regional.

Otros dos ejemplos, desde la historia de comunidades de cultivadores, enriquecen los modos de apreciación de esta región como paisaje cultural, desde este otro perfil vinculable a la historia de la agricultura.

Un último caso, ejemplificando la catalogación de recursos culturales que fundamentan un lugar, para su comprensión territorial patrimonial y la faz propositiva, de proyectos de circuitos turístico-patrimoniales para su desarrollo.

Palabras clave: forma, territorio, paisaje, patrimonio 


\section{ID INVESTIGACIONES}

\section{ABSTRACT}

Reading of the history of the territory through their forms, and understanding of the concept of heritage at the level of the territory, from the territorial identities of the "Litoral del Río Uruguay" region.

Observation of various modes of interchange between water and earth, sensed elements of this territory, and the multiplicity of forms built as a place of life and work, by resident human communities.

Two cases, illustrative of the history of cattle, leather and meat, that from common roots have developed different processes, building the diversity of this profile of regional cultural landscape.

Two other examples, from the history of growers communities, enrich the appreciation modes of this region as a cultural landscape, from this specific profile concerning the history of agriculture.

One last case, exemplifying a catalogue of cultural resources to guide understanding the territorial heritage of a place and the proposal of touristicheritage circuit projects for development.

Key words: form, territory, landscape, heritage

\section{DOS CONCEPTOS, CINCO CASOS, ALGUNAS CONCLUSIONES}

El tema presentado se construye a partir de dos conceptos. Uno, surgido desde la cátedra, que explica la línea de enseñanza e investigación que lo fundamenta. Otro, fundado en el lugar, cuya sugerente diversidad territorial, ha motivado la continuidad de la selección de casos de análisis.

Uno ha aportado la necesaria metodología y su enriquecimiento a partir de la puesta en práctica durante una década. El otro, el estimulante reconocimiento 
ID_INVESTIGACIONES

de los valores patrimoniales del ámbito territorial considerado, ha retroalimentado a su vez, nuevas cuestiones metodológicas a profundizar.

Los cinco casos seleccionados, además de su diversidad, presentan una descripción intencionada, que pone el acento en la lectura y comprensión de sus valores como territorios patrimoniales.

Al finalizar, algunas conclusiones con énfasis en aspectos de la reflexión metodológica, presentadas de modo abierto. llustrando un debate en proceso, que apunta a la mejor apreciación de este perfil disciplinar, como estimulante aporte a la interpretación del territorio para su proyecto y ordenación.

\section{CONCEPTO UNO: desde la cátedra}

La lectura de la historia del territorio a través de sus formas como cuestión de la disciplina arquitectónica, y especialmente, la comprensión del concepto de patrimonio a escala del territorio, asociados al estudio e investigación de las identidades territoriales de la región Litoral del río Uruguay, son enfoques centrales de la actividad del grupo docente de la Cátedra de Historia de la Arquitectura Nacional en Salto, en sus prácticas desde hace una década.

Subrayamos el valor de la observación en el estudio, en tanto el territorio es en primer lugar un hecho visible, un resultado material, reconocible por sus formas. Inicialmente formas naturales, sobre las que se fueron incorporando paulatinamente formas artificiales, construidas. Tan sencillas como senderos, cercos y alambrados, o tan complejas como carreteras, calles y edificios. Que en última instancia, reflejan la voluntad de su comunidad, resultado de sus deseos y también de sus conflictos.

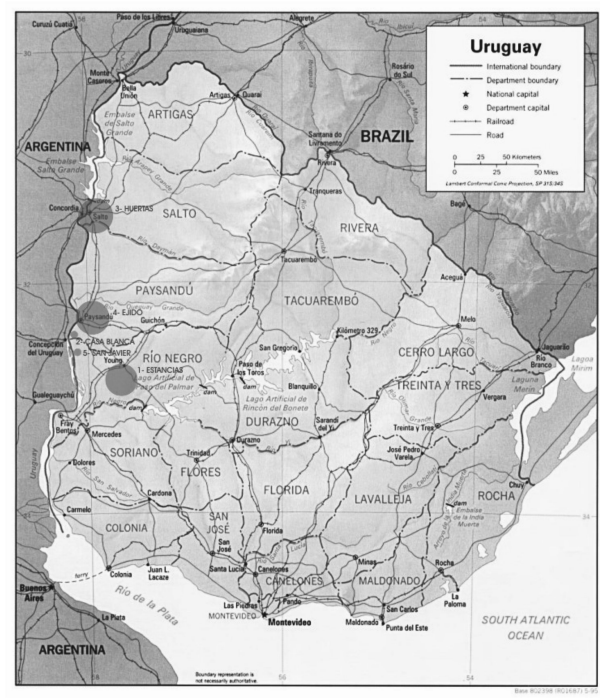

Mapa regional y ubicación de casos 


\section{ID_INVESTIGACIONES}

Estas transformaciones, estas construcciones, se acumulan con el transcurrir del tiempo, y adquiere importancia la comprensión de este proceso como historia del lugar. En consecuencia, nos interesa la observación y el estudio de las formas del territorio, a lo largo de su historia, entendiendo que cosas han permanecido o no, que se ha alterado o no, y por lo tanto, apreciando las jerarquías y valores diferentes de esas formas.

Observado así, se destaca que el territorio no es indiferente, que la forma de un determinado territorio, posee un conjunto de características propias y exclusivas, que se han ido acumulando en el tiempo, indicándonos que la herencia de ese territorio, que constituye su genealogía, es un valor en sí, y es observable. Es su paisaje.

Entonces, a la escala de un territorio, aprender a observar y reconocer sus cualidades singulares e insustituibles, nos facilitará la posibilidad de discernir cuales de esas formas del territorio considerado, constituyen su patrimonio.

\section{CONCEPTO DOS: desde el lugar}

Agua y tierra son fundamento y esencia del territorio que nos interesa.

Observar los variados modos de su interrelación, y la multiplicidad de formas construidas como lugar de vida y trabajo, por las comunidades humanas que lo habitan.

Estas cuestiones, atraen nuestra mirada como técnicos afincados desde hace muchos años y motivan este tipo de estudio.

La naturaleza del agua, desde la forma del gran río para la navegación y el transporte fluvial, sus ríos afluentes, arroyos, cañadas y lagunas, conforman la riquísima red acuática de esta gran región litoral, que posibilitó los primeros 


\section{ID_INVESTIGACIONES}

afincamientos y el desenvolvimiento de la vida de trabajo de las comunidades, desde hace vario siglos.

La naturaleza de la tierra en esta región, explicada bajo forma de fértil pradera natural, que viabilizó el fenomenal procreo espontáneo de ganado vacuno introducido durante la Colonia, el mejoramiento genético decimonónico y la persistencia y crecimiento hasta el presente, en suelos del más alto valor productivo en el país.

A lo largo de esos innumerables cursos de agua, encontramos montes nativos ribereños, cuya madera posibilitaría la construcción de las primeras habitaciones y lugares de trabajo, aplicando técnicas con barro.

Los suelos ganaderos transformados en chacras, ya en el siglo XX, mediante el laboreo para la agricultura extensiva o intensiva, por el valioso aporte cultural de grupos inmigrantes tradicionalmente acostumbrados a plantar hortalizas 0 cereales.

Las aguas profundas y los recodos al abrigo que jalonan las costas del gran río, desde donde fueron construyéndose las formas de los puertos sobre ambas márgenes y luego surgirian las fábricas de la carne, en saladeros primero y luego frigoríficos del novecientos.

Estas y muchas otras formas construidas en el tiempo, transformando los elementos naturales originales con creciente complejidad, componen las marcas de identidad de la historia de los paisajes culturales del Litoral del río Uruguay. Vastísima región estructurada a lo largo de cientos de kilómetros en dirección norte-sur por el gran río; que sería incomprensible no obstante, sin referirse a las fértiles y extensas tierras de su cuenca, hacia este y oeste.

Estas dos vertientes conceptuales, que han sido desarrolladas, revisadas y profundizadas durante los últimos años, guían la presentación actual de este 
ID_INVESTIGACIONES

trabajo, que resulta una imagen instantánea presente en un proceso de conocimiento e investigación del territorio regional, denotando su propio carácter de "construcción" teórica. El desarrollo a continuación de algunos de los casos abordados, permitirá explicar estos enfoques que han evolucionado asociados.

\section{CASO UNO / ESTANCIAS, RÍO NEGRO Y SALTO}

Habiendo sido el primero en el tiempo, el caso particular de la arquitectura del medio rural, presenta el interés complementario de ser un área poco investigada y documentada, que desde nuestra ubicación en la región litoral estamos en mejores condiciones de encarar (Cátedra HAN Salto, 2000) y que apuntó en primera instancia, a casos en los departamentos de Salto y Río Negro.

Comprensión del valor tipológico de la "estancia", unidad económica del modelo agroexportador capitalista del siglo XIX; pero desde nuestra mirada, fundamentalmente, unidad territorial de la vida rural. Verdadero microcosmos construido de múltiples componentes, transformador de la naturalidad primigenia. Allí, la casa principal habitualmente destaca por su expresión arquitectónica, pero importa más aún "el casco", "las casas", es decir, el conjunto edificado que integran las viviendas del personal, galpones diversos y los edificios y equipamientos imprescindibles para esta vida rural ganadera vacuna y luego también lanar (bretes, embarcaderos, etc.). Que comprende invariablemente además, el exterior acondicionado con patios, senderos, arboledas diversas y elementos que ayudan a regular fríos y calores, vientos y Iluvias, construyendo el dilatado y singular espacio de transición que identifica los sitios de la vida rural. En fuerte contraste con el paisaje extenso y de perspectiva casi infinita tan característico de estos territorios.

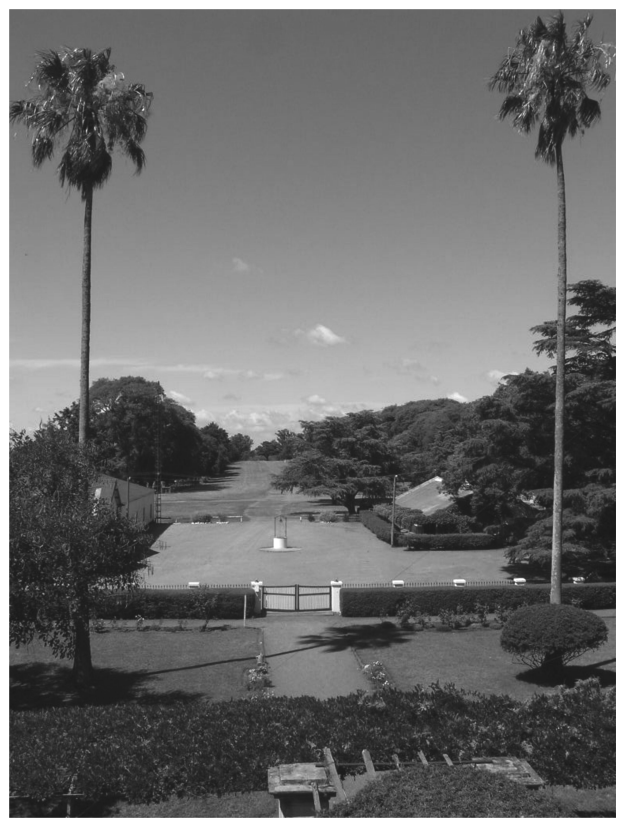

Estancias en Río Negro 


\section{ID_INVESTIGACIONES}

Con el avance del estudio en torno al tema, creció, a su vez, el interés por este caso y sus innumerables sitios particulares. Comprendiendo como la tierra, como valor natural y génesis de la ganadería nacional, se vinculará con el agua, apreciada como medio de transporte fluvial. En un germinal proceso de calificación de ese espacio de la tierra, como pradera, campo, estancia. Sumándose el espacio del agua, como río, costa, embarcadero, puerto. En esa interacción de formas que gesta la construcción y organización del territorio litoral y signará uno de sus perfiles como paisaje cultural.

Al valor original de las praderas naturales, apreciado por Hernandarias durante la Colonia, que posibilitará el maravilloso procreo natural del ganado introducido, hace justamente 400 años; se sumará el aporte inmigrante británico del siglo XIX, innovador de la genética ganadera en las estancias del centro del departamento de Río Negro. En la costa, en tanto, las extraordinarias condiciones naturales del sitio de Fray Bentos como puerto. $Y$ su salto cualitativo, fruto de la industrialización de la carne, tras la instalación de la fábrica Liebig's Extract of Meat en 1868. Valiéndole el renombre internacional a la marca $L E M C O$ y el reconocimiento del sitio como "Ia Gran Cocina del Mundo" (Barrios Pintos, 1959). Que se continuará, tras su transformación tecnológica como frigorífico Anglo, a comienzos del novecientos, hasta más allá de la mitad del siglo veinte.

No ahondaremos ahora, en la descripción o análisis del complejo Liebig'sAnglo, afortunadamente hoy ya más estudiado, y con propuestas de ordenamiento y protección patrimonial, apuntando a la postulación como Patrimonio de la Humanidad.

Fundamentalmente conviene recalcar su indisoluble vínculo con el desarrollo de las estancias en las tierras cercanas al río Uruguay, a veces ubicadas tan distantes de la fábrica, en el Norte argentino, o Sur paraguayo. Proceso que no se comprendería, sin comenzar por analizar la paulatina aparición de los 


\section{ID_INVESTIGACIONES}

saladeros como primeras "fábricas de la carne" del siglo XIX, sobre ambas costas del río. Temática que ya vislumbrara en sus Trabajos Prácticos de Curso 1997 la Cátedra de Historia de la Arquitectura Nacional de Salto.

Que explica una cierta construcción de este territorio a partir del intercambio generado desde las singularidades de este suelo y esta agua. Comprensible como paisaje cultural que podría sugerir, tal como se desarrollara en trabajo anterior, la denominación de "Historia de la Producción Ganadera", como posible ejemplo para la "aplicación de recursos patrimoniales a planes de desarrollo local" (Castelli, García da Rosa, Levin, 2003).

\section{CASO DOS / CASA BLANCA, PAYSANDÚ}

En ese peculiar ámbito que es la costa como espacio de interfase entre agua y tierra, entre lo natural y lo construido, Casa Blanca, a orillas del río Uruguay y $15 \mathrm{Km}$. al Sur de la ciudad de Paysandú, es otro caso que presenta indudable atractivo como sitio de acumulación cultural en la micro-región sanducera. Que vale la pena observar desde las dos miradas diferentes y complementarias, coexistentes a través de su historia. Vigentes, aunque diferentes, aún hoy.

En relación al río. Mirado desde y hacia el Oeste. Componente del gran espacio territorial fluvial norte-sur, que involucra ambas márgenes, oriental y occidental. Uruguaya y argentina hoy, pero ya caracterizadas en la época colonial, mucho antes de la definición de las fronteras nacionales.

En relación al campo. Mirado desde y hacia el Este. Con sus cabeceras portuarias, urbanas, de un vasto territorio rural agropecuario, estructurado por un loteo productivo reconocible en su historia.

Dentro de este territorio, Casa Blanca es relevante síntesis peculiar entre naturaleza y cultura. Resultado singular de una historia de diálogos entre una

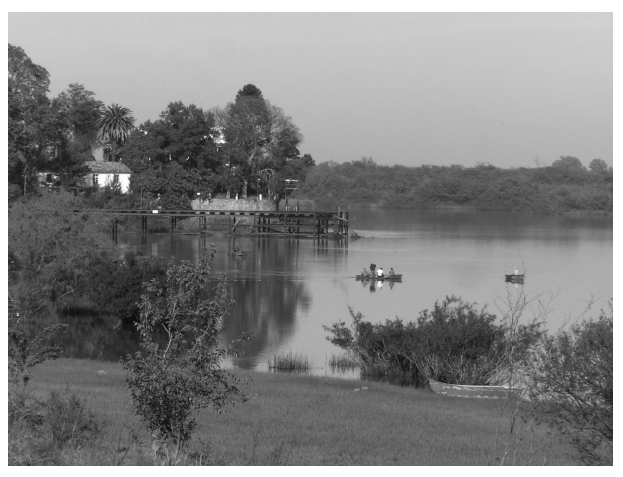

Casa Blanca, Paysandú 


\section{ID_INVESTIGACIONES}

forma del agua y una forma de la tierra, entre el río y la pradera, entre el puerto y la estancia, entre la carne y la fábrica.

Destaca por las distintivas calidades visuales naturales de esta ancha sinuosidad del río jalonada por los dos grandes islas del Paso Almirón. Pero es igualmente apreciable, como sumatoria de fábrica y pueblo obrero. Originalmente saladero, luego adecuado tecnológicamente a frigorífico y aún hoy en plena actividad como característica exclusiva, transcurridos doscientos años.

Al recorrerlo, fácilmente tentaría vincularlo a la idea de "company-town" aplicada a la industria de la carne, presente en otros valiosos sitios a lo largo del Río Uruguay. El Liebig's-Anglo sobre la costa oriental uruguaya al sur de Fray Bentos, o el Pueblo Liebig sobre la margen occidental argentina al norte de Colón. Y que en este caso, sin embargo, curiosamente no posee orígenes británicos.

A la apreciación como conjunto patrimonial de valor natural y cultural, se suman particulares valores a escala edilicia. La Casa de los Cuatro Vientos, uno de los insoslayables hitos construidos del sitio, implantada sobre el extremo más saliente y más elevado de esta costa de río. La peculiar conformación y silueta de la Capilla Santa Ana y la sencillez formal y el porte del Almacén de Ramos Generales; ambos ubicados en sitios destacados dentro del sector más antiguo del Barrio Obrero, Y completando el espectro, sin duda, las propias Viviendas Obreras, con el atractivo de su reconocible unidad tipológica y visual en sus dos sectores de implantación.

Como se puede constatar entonces, el análisis de estos dos primeros casos ilustra la historia de la ganadería, del cuero y la carne, que registra múltiples ejemplos en el litoral. Desde una raíz común, observamos que han desarrollado procesos diferentes, que construyeron la diversidad de este perfil de paisaje cultural de dilatadísima extensión. 


\section{ID_INVESTIGACIONES}

Vale la pena indicar, además, que en la mayor parte de estos casos, la propia tarea inicial de relevamiento y registro gráfico en estos lugares, ha constituido un logro en sí mismo, debido a su inexistencia previa.

El proceso de construcción conceptual de este enfoque motivará a la cátedra de Historia de la Arquitectura Nacional de la Sede Salto de la Facultad de Arquitectura, para continuar desarrollando su actividad curricular en torno a nuevos temas afines. Seleccionando y abordando en los cursos otros calificados ámbitos dentro de este vasto territorio regional del Bajo Río Uruguay sobre ambas márgenes, para su relevamiento, investigación y calificación patrimonial. A las estancias, saladeros y frigoríficos, se irán sumando paisajes agrarios de génesis diferente, que analizaremos a continuación.

\section{CASO TRES / EJIDO DE CHACRAS, PAYSANDÚ}

Conocer el extendido Ejido de Chacras, contiguo a la ciudad de Paysandú, nos vincula con un territorio rural cercano a un centro urbano; cuya apreciación, su historia, evidencian características diferentes y el reconocimiento de formas de singularidad propia relacionadas con el trabajo agrario. Con su eje caminero de Oeste a Este, su gran traza cuadricular modernizadora y los evocativos nombres de las colonias gestadas en su entorno.

La fuerza de la geometría del gran damero rural de Paysandú, proyectado por el agrimensor Delort a fines del siglo XIX, constituye una marca propia de este lugar. Entender su historia, recorriéndolo, muestra su capacidad de adecuación y calificación, desde las características naturales de cada pequeño sitio en él. Observándose como la cuadrícula original, neutra y abstracta, se ha hecho ruta o avenida, bien pavimentada y transitada. Contundente traza recta, respaldada por alineaciones de árboles; o levemente sinuosa, adaptándose a algún

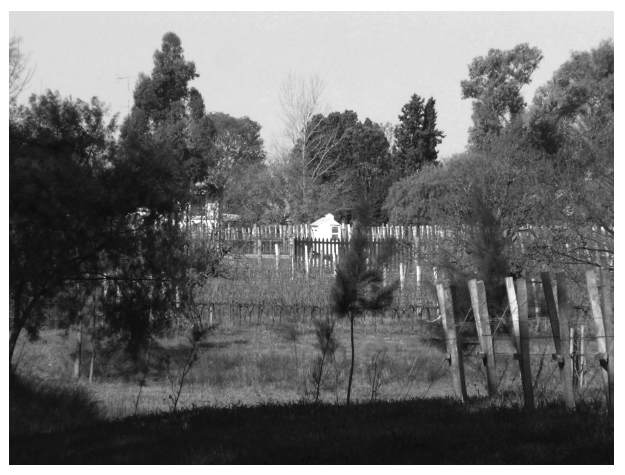

Ejido, Paysandí 


\section{ID INVESTIGACIONES}

accidente pequeño. Sendero que va desapareciendo en la tierra húmeda de los bajos; o calle a modo de rambla, acompañando las márgenes de los arroyos.

Por las características de la propuesta formal de organización del territorio y por la época en que se realizó, sin duda nos recuerda acciones colonizadoras en damero de gran escala en territorios no muy lejanos en Argentina, entrerrianos, o aún cordobeses (Colonia Caroya, por ejemplo).

Coincidentes en el tiempo, en Uruguay, el reglamento para el Trazado de Pueblos y Colonias de Melitón González de 1877 y en Argentina, la aplicación de la denominada Ley Avellaneda de 1876 de fomento de la inmigración y la colonización, evidencian la significación del pensamiento racionalista como modelo urbanizador de la época republicana decimonónica. Indicativo de la trascendencia de la idea de ciudad cuadricular, impuesta a escala continental con el damero de las Leyes de Indias, mucho más allá del dominio español colonial.

Leyes que ilustran igualmente, el fomento de la inmigración europea para la colonización del territorio, promovido por el modelo civilizador y modernizador de los gobiernos de las repúblicas nacientes. Que se reflejan en las mismas sugerentes denominaciones de los emprendimientos colónicos locales, como Esperanza, Porvenir, Constancia.

\section{CASO CUATRO / HUERTAS, SALTO}

El extenso territorio del cordón hortofrutícola que rodea la ciudad de Salto, es el más reciente caso abordado, en pleno proceso de estudio. También claro ejemplo de singulares condiciones naturales de tierra y clima, que el arribo de un peculiar modo de trabajo inmigrante (italiano, portugués, vasco) supo aprovechar y desarrollar desde fines del siglo XIX, hasta este presente de plena actividad. 


\section{ID_INVESTIGACIONES}

Las tierras arenosas y la mayor amplitud térmica del clima en el norte del país constituyeron las condiciones naturales adecuadas. Pero sin el afincamiento de un grupo humano con una cultura incorporada de generaciones para el laboreo de la tierra, este proceso no se habría desencadenado y mantenido en el tiempo, como modo de vida y paisaje de trabajo, que ha ido asimilando la necesaria innovación tecnológica.

En una primera mirada, de forma dominante, un paisaje de trabajo construido desde la tierra, desde la cultura agraria europea inmigrante, pero cuya existencia sería inimaginable sin la generosa disponibilidad de agua.

Paisaje de formas agrarias de fuerte geometría, pautada por la linealidad de los surcos de las huertas y la sucesión de árboles frutales. El plano elevado de las cortinas de árboles para cobijar los plantíos de los vientos y consecuentemente, caracterizar los caminos interiores. Por lo tanto, paisaje de cercanías, de visuales acotadas. Las tecnologías de más reciente incorporación, le han agregado diferentes siluetas traslúcidas de grandes invernáculos, túneles, micro-túneles y sombreados.

A la singularidad del paisaje de plantaciones de hortalizas, frutales y viñedos, se agregan las "marcas" de identidad salteña, que agregan algunas de las especies en particular. Las frutillas y las naranjas como ejemplos notorios. Y específicamente, en el marco del resurgimiento reciente de la cepa tannat como marca del vino uruguayo difundida a nivel internacional, no puede olvidarse que aquí, hace unos 150 años, el inmigrante vasco francés Pascual Harriague desarrolló las primeras plantaciones. Observándose hoy en el paisaje, nuevos emprendimientos vitivinícolas locales, con productos de significativa calidad.

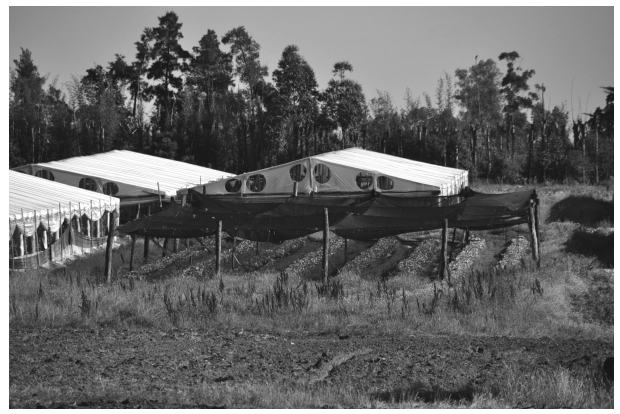

Huertas en Salto 


\section{ID_INVESTIGACIONES}

Al recorrer este lugar, al explicarlo, sin duda también podrían recordarse referentes de paisajes culturales similares en parques agrarios europeos, como el Parc Agrari del Baix Lobregat, en Catalunya, muy cercano a Barcelona.

Con mirada similar a como concluíamos la descripción de casos vinculados a la historia de la producción cárnica, aquí también, nos encontramos ante varios otros ejemplos referenciales, que ahora desde las historias agrarias de comunidades de cultivadores, demuestran a partir de un tema de génesis común, el desenvolvimiento de construcciones territoriales diversas, que enriquecen los modos de apreciación de esta región en términos de paisaje cultural en este caso vinculable a la historia de la agricultura.

\section{CASO CINCO / SAN JAVIER, RÍO NEGRO}

Abordado ya desde hace varios años, el conocimiento personal previo del área del Pueblo San Javier y colonias cercanas, en la zona costera del departamento de Río Negro sobre el río Uruguay, permitía vislumbrar la posibilidad de encarar diferentes escalas y cualidades distintivas del lugar, que presentaban sumo interés para el análisis y la sistematización temática desde nuestra cátedra.

De modo sintético, se puede expresar que esta área dentro de la región litoral noroeste presenta, en una escala de observación territorial patrimonial, una singularidad de sitio construida por la colonización rusa allí afincada desde su desembarco el 27 de Julio de 1913. Donde la descripción de recursos territoriales que componen la génesis de este lugar, puede poner el acento en el arribo pionero y su contenido religioso, las especificidades culturales de la gastronomía conservada, e igualmente, otras fuertes expresiones trasladadas y

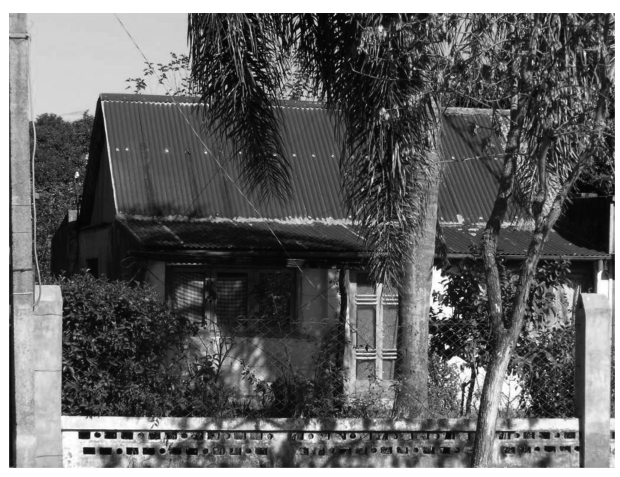

San Javier, Río Negro 


\section{ID_INVESTIGACIONES}

mantenidas, como el cultivo del girasol, que introdujeron en nuestro país. Desde una escala de análisis edilicia, las peculiaridades de la vivienda construida, con técnicas constructivas conocidas adaptadas con peculiaridad cultural en el lugar, cuyos numerosos casos ameritan su calificación patrimonial.

En la primera experiencia de rápido reconocimiento de este centro poblado, destacan edificios sencillos, pero de mayor porte, como la Casa Blanca (casco de la antigua estancia) donde residió el líder religioso y el templo Sabraña de dicha congregación, representativos del arribo colonizador pionero.

La observación detenida a escala edilicia, posibilita el análisis de los múltiples casos de los denominados "ranchos rusos", dentro del Casco urbano del pueblo San Javier. Ejemplos numerosos y diversos de viviendas existentes con tipología similar, representativas del modo de vida del asentamiento de los inmigrantes rusos. Construidas con barro y troncos o maderas del lugar, pero cuyo diseño podría referir a la "itsbá", cabina de madera originaria de Rusia.

Por un lado, la constatación de la multiplicidad de casos observables, permite calificarlo como un elemento caracterizador de esta estructura urbana, ameritando su estudio, ya desde este punto de vista. La puesta en valor de este tema, permitiría contemplar una etapa siguiente de evaluación y selección de un caso representativo de esta tipología, para proyectar su restauración y exponer demostrativamente el modo de vida de la familia rusa colonizadora. Cabe recordar aquí, referentes como la Casa Museo Friuli en la Colonia Caroya, Córdoba.

Complementando su singularidad, este ámbito se vincula con la recientemente designada Área Natural Protegida de los Esteros de Farrapos e Islas del Río 


\section{ID INVESTIGACIONES}

Uruguay, humedal de excepcionales características, que abarca cerca de 6.000 hectáreas extendidas a lo largo de unos $50 \mathrm{Km}$ junto al río Uruguay. Agregando una interesantísima posibilidad de apreciación territorial desde una dimensión ambiental integradora.

Surgida la oportunidad de abordar el estudio territorial a mayor escala, abarcando la totalidad de la microrregión del Área Natural Protegida de Esteros de Farrapos e Islas del Uruguay y las áreas urbanas vecinas (San Javier, Nuevo Berlín); conceptualmente, la catalogación de los recursos culturales para la comprensión de esta microrregión, reconoce, en primer lugar, los dos grandes capítulos -la Naturaleza y la Colonización- que fundamentan este lugar.

En la etapa propositiva, partiendo de cada uno de ellos, se desarrollan proyectos de circuitos turístico- patrimoniales que ilustran sus respectivas diversidades.

La mirada hacia la Naturaleza en el área cercana a San Javier, por ejemplo, enfatiza en los temas del río, las islas, el estero, el monte galería, la playa, aislados o vinculados entre sí, en los Caminos de Interpretación Natural.

Del mismo modo, al referir a la colonización, se pone el acento en los diversos temas ya referidos, agrupados finalmente, en los Caminos de Interpretación Pionera, que nuclean edificios comunitarios, ranchos rusos, gastronomía y artesanías.

En un tercer nivel, los Caminos de Interpretación Agraria, compendian la tradición horticultora rusa, el cultivo del girasol introducido y los significativos edificios productivos construidos con tal fin, como el Galpón de Piedra y el Molino aceitero, junto al puerto nuevo para embarcar Río Uruguay abajo, lo producido. 


\section{ID_INVESTIGACIONES}

\section{ALGUNAS CONCLUSIONES}

En resumen, apuntando a contribuir a la apreciación de los territorios patrimoniales, o paisajes culturales, este trabajo reivindica, particularmente el valor de la observación y el estudio de la forma como especificidad disciplinar de la arquitectura. Algo que podría resultar obvio pero creemos conviente reafirmar. $Y$ en el mismo sentido, el reconocimiento del territorio como hecho formal, cuyo estudio, pone en evidencia la construcción cultural de la comunidad a lo largo de su historia.

No obstante, podría considerarse éste un ejercicio descriptivo, una ilustración de hermosos sitios, mayormente poco conocidos y difundidos. Con fuerte acento de naturalidad en algunos momentos y notoria evidencia de construcción cultural patrimonial, mayormente.

Por lo pronto, conviene enfatizar que la propia descripción nunca es neutra. Se encara desde una determinada perspectiva, lo cual implica posicionamiento y sesgo de valoración. Aporta entonces, un modo de observar el territorio, su historia, como aspecto metodológico novedoso. Pero aún más, como ya se ha referido, constituye una nueva herramienta para el ordenamiento del territorio, anclada en la apreciación patrimonial a esta escala, y desde la cual, construir una propuesta para el desarrollo de las pequeñas comarcas, fundada en su identidad.

Los casos explicados permiten comprender como este modo de estudio del territorio, posibilita hallar patrones de asentamiento representativos de cada modo cultural de actuar en el espacio a lo largo del tiempo, que servirán para definir criterios de ordenación. De tal manera que la descripción morfológica del territorio asume un valor propositivo que constituye una definición metodológica primordial como herramienta para la ordenación. 


\section{ID INVESTIGACIONES}

En el marco de este enfoque metodológico, interesa desarrollar una operativa para la apreciación morfológica del territorio que ponga el acento en la identificación de sus distintos componentes formales, naturales y construidos. Una síntesis dinámica de la gama y especificidad de las formas naturales del territorio considerado, sus relieves, sus suelos, sus cursos de agua, y la diversidad de formas construidas resultantes de la intervención humana sobre él, sus parcelarios, sus vías, sus poblados. Entrelazándolos de manera tal, que se haga visible la historia de su acumulación y transformaciones mutuas, es decir la genealogía de este territorio como patrimonio del lugar.

En definitiva, y sobre todo, el énfasis en el concepto de patrimonio del territorio para abordar la comprensión del territorio desde sus formas identitarias, subraya su condición de herencia colectiva, de modo tal, que a la hora de la intervención física sobre él, se sepa relativizar la propuesta como una instancia más en su larga historia, como postura técnica y actitud ciudadana deseables, respetuosas y responsables por su acción novedosa. El sentido de esta responsabilidad a la hora de la actuación profesional, finalmente, es una actitud hacia la integridad del ambiente, como sitio de vida.

Significativamente este tipo de abordaje para el ordenamiento del territorio creemos presenta el desafío de equilibrar sensibilidad con rigor metodológico. Sensibilidad, necesaria para observar, desentrañar y calificar los valores formales identitarios del lugar, reconocidos y asimilados por sus habitantes. Rigor metodológico, para organizar este inventario y luego concretar una propuesta congruente y viable de desarrollo local, apropiable por la comunidad. Dos cuestiones, que no está mal destacar y reiterar hoy, que deben fundamentar nuestra disciplina arquitectónica. 
ID_I N VESTIG ACIONES

\section{BIBLIOGRAFÍA}

Metodología

CORBOZ, André. 1983. "El territorio como palimpsesto".

EIZAGUIRRE GARAITAGOITIA, Xabier. 1990. "Los componentes formales del territorio rural”. Tesis Doctoral ETSAB UPC. Director de la Tesis: Dr. Manuel de Solá-Morales. Biblioteca UPC ETSAB: R-T-Eizaguirre / 1210028031.

EIZAGUIRRE GARAITAGOITIA, Xabier. 2003. "El territorio como arquitectura". "De la geografía a la arquitectura del territorio". Copia del original electrónico cedida por el autor en Noviembre 2005

GREGOTTI, Vitorio. 1972. "El territorio de la Arquitectura”. Colección Arquitectura y Crítica,

SABATÉ BEL, Joaquín. 1998. "El patrimonio de la forma del territorio como criterio de ordenación". Revista Ciudades No. 4, "Territorio y Patrimonio". Instituto de Urbanística de la Universidad de Valladolid.

SABATÉ BEL, Joaquín. 2002. "En la identidad del territorio está su alternativa". Copia del original electrónico cedida por el autor en Abril 2004.

SOLA-MORALES, Manuel de y PARCERISA Josep. 1981. "La forma de un país", en Revista Quaderns d’Arquitectura i Urbanisme No. 1 Extra. Publicación Oficial del Colegio de Arquitectos de Cataluña, Barcelona.

Región

ALVAREZ LENZI, Ricardo. 1972. "Fundación de poblados en el Uruguay". Facultad de Arquitectura. Universidad de la República. Montevideo.

BARRACCHINI, Hugo. 1978. "Historia de las comunicaciones en el Uruguay". Facultad de Arquitectura. Universidad de la República. Montevideo.

CAMPAL, Esteban, 1994. “La Cruz y el lazo”. Ediciones de la Banda Oriental. Montevideo

KLACZKO, Jaime y RIAL, Juan. 1981. "Uruguay: país urbano”. CLACSO - Ediciones de la Banda Oriental. Montevideo. 
ID_I N VESTIG ACIONES

MÉNANTEAU, Loïc. 2005. "Le Patrimoine Culturel et Industriel du Bas-Uruguay (Argentine, Uruguay): typologie, spécificités et potentialités touristiques". Universidad de Nantes.

MURAS, Otilia. 1983. "Colonización agraria en el Uruguay". Facultad de Arquitectura. Universidad de la República. Montevideo.

\section{Departamentos}

BARRIOS PINTOS, Aníbal. 1959. "Río Negro en el Centenario de Fray Bentos”. Álbumes departamentales. Editorial Minas. (Páginas sin numerar)

BARRIOS PINTOS, Aníbal. 2005. "Río Negro. Historia General”. Intendencia Municipal de Río Negro.

COLECCIÓN LOS DEPARTAMENTOS: "Río Negro". 1970. Wettstein, G. y Campodónico, C. (Coordinadores). Editorial Nuestra Tierra. Montevideo

COLECCIÓN LOS DEPARTAMENTOS: "Río Negro”. 1998. Galván Gloria (Coordinadora). Editorial Fin de Siglo. Montevideo.

"Plan de Desarrollo y Ordenamiento Territorial de la Micro Región de Fray Bentos". 2008. Convenio MVOTMA-DINOT e Intendencia Municipal de Río Negro.

COLECCIÓN LOS DEPARTAMENTOS: "Paysandú". 1970. Wettstein, G. y Campodónico, C. (Coordinadores). Editorial Nuestra Tierra. Montevideo

“Paysandú. Álbum de El Diario”. 1933. Imprenta Latina. Montevideo.

PEREDA, Setembrino. 1896. "Paysandú y sus Progresos". Imprenta El Siglo llustrado. Montevideo.

SCHULKIN, Augusto. 1958. "Historia de Paysandú. Diccionario Biográfico". Editorial Von Roosen. Buenos Aires.

COLECCIÓN LOS DEPARTAMENTOS: "Salto". 1970. Wettstein, G. y Campodónico, C. (Coordinadores). Editorial Nuestra Tierra. Montevideo

MEVIR. Unidad de Estudios Territoriales. 1999. "Cordón Hortifrutícola de Salto". Área Natural Protegida 


\section{ID INVESTIGAC I O NES}

FACULTAD DE CIENCIAS - DINAMA (Convenio). 2002. "Pautas para la elaboración de un Plan de Manejo para el Área de Esteros de Farrapos. Primera parte: Medio Físico y Fauna. Informe Final". Universidad de la República - Ministerio de Vivienda Medio Ambiente y Ordenamiento Territorial, Montevideo.

URDIALES ALONSO, Carlos. 2006. "Propuesta de delimitación y zonificación de futuras áreas protegidas en el Río Santa Lucia y Esteros de Farrapos e Islas del Rio Uruguay". Técnico de Conservación. Parque Nacional de Doñana. Consejería de Medio Ambiente. Junta de Andalucía. España.

VIDA SILVESTRE URUGUAY. 2008. Productos Nos. 2 y 3 - Sitio Ramsar Esteros de Farrapos e Islas del Río Uruguay. Informe de asistencia técnica para el Proyecto SNAP.

Investigaciones y proyectos con participación personal

EQUIPO TALLER RÍO NEGRO. 2002. "Algunas cuestiones para el abordaje del planeamiento territorial y el desarrollo del departamento de Río Negro". Maestría de Ordenamiento Territorial, Facultad de Arquitectura, Universidad de la República. Montevideo.

CASTELLI, Walter; Levin, Marianela, García da Rosa, Adolfo. 2003. "Las Formas de la Costa del Río de los Pájaros Pintados" y "La Historia de la Producción Ganadera". "Aplicabilidad al área del Departamento de Río Negro de la metodología de los planes territoriales de aproximación morfológica como criterio de ordenación y recursos patrimoniales como base de desarrollo regional". Maestría de Ordenamiento Territorial. Facultad de Arquitectura, Universidad de la República. Montevideo.

CASTELLI, Walter. 2005. "Río Negro, un territorio modelado por los cambios rurales". Tesis en curso y proyecto de investigación del territorio, en este caso rural, con enfoque patrimonial, observando las formas del paisaje como hecho cultural. Maestría de Ordenamiento Territorial. Facultad de Arquitectura. Universidad de la República. Montevideo.

"Programa de Desarrollo Urbano de la ciudad de Young". 1988 y 1990. Convenio Facultad de Arquitectura e Intendencia Municipal de Río Negro. Integrante del equipo técnico local. 
ID_INVESTIGACIONES

Plan Urbanístico de la ciudad de Paysandú". 1994 y 1997. Convenio Facultad de Arquitectura e Intendencia Municipal de Paysandú. Integrante del equipo técnico del Instituto de Teoría y Urbanismo (ITU).

"Revisión Plan Urbanístico de Paysandú y Elaboración Plan Desarrollo y Ordenamiento Territorial de Paysandú y Microrregión". 2008. Integrante del equipo del Arq. Salvador Schelotto. Asesor local en ordenación del territorio, patrimonio y paisaje cultural.

CASTELLI, Walter. 2008. "San Javier. La tipología de vivienda "Rancho Ruso”. Cátedra de Historia de la Arquitectura Nacional. Facultad de Arquitectura, Universidad de la República. Sede Salto. Investigación en proceso

CASTELLI, Walter, 2009. "Proyecto de Rehabilitación del Galpón de Piedra de San Javier para Centro de Visitantes del Área Natural Protegida Esteros de Farrapos e Islas del Río Uruguay: a) Proyecto Arquitectónico; b) Propuesta de líneas de Ordenamiento Territorial de la Microrregión; c) Propuesta de Circuitos Turístico-Patrimoniales ". Convenio Sistema Nacional Áreas Protegidas (MVOTMA) y Parques Nacionales de España. 


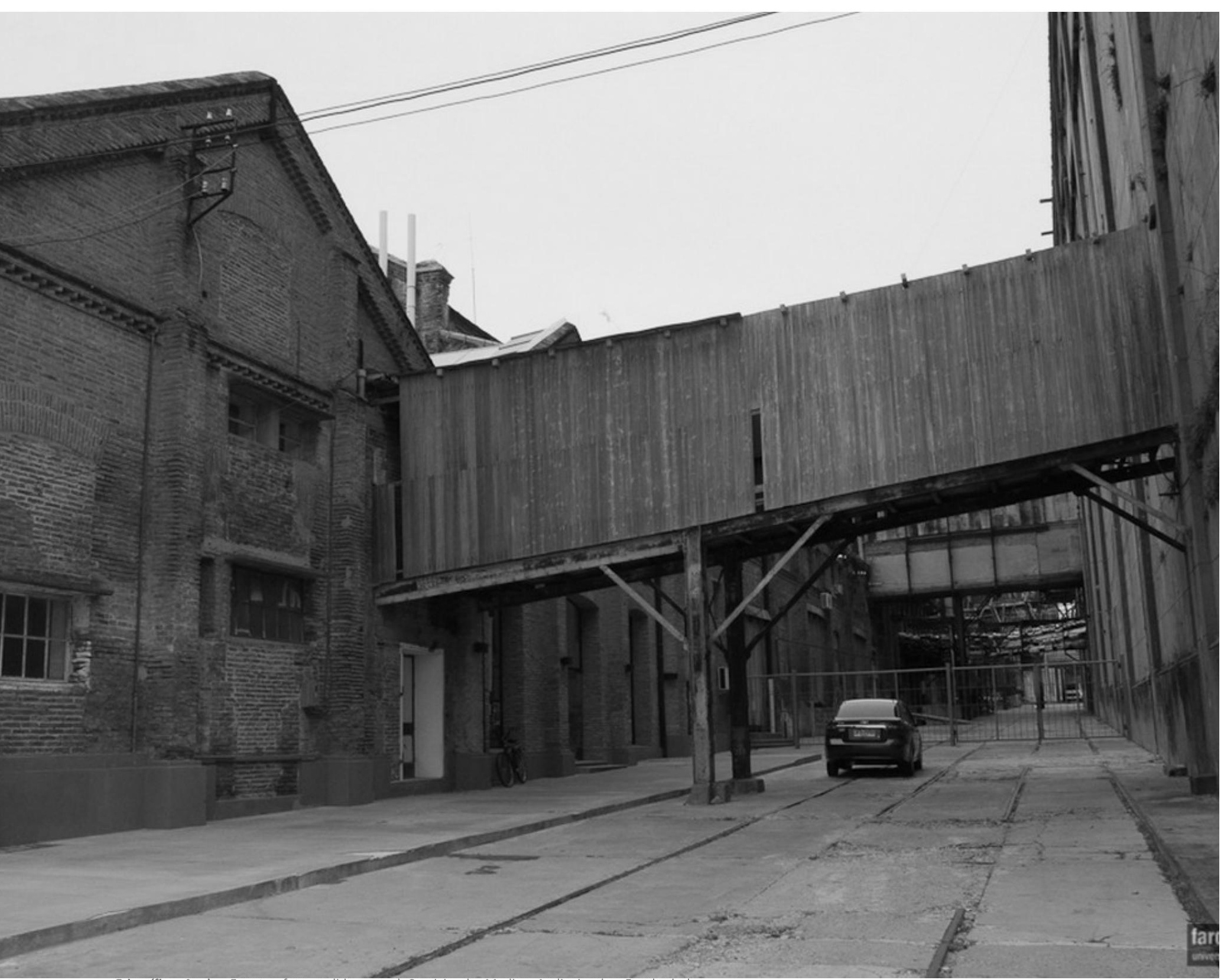

Frigorífico Anglo. Fuente: foto cedida por el Servicio de Medios Audiovisuales Facultad de

Arquitectura, autora Silvia Montero 